\title{
Pioneiras do Serviço Social: um estudo de perfil a partir das relações de gênero
}

\author{
Pioneers of Social Work: a profile study based on gender relations
}

\author{
Jessica Flores Mizoguchi* \\ Thaisa Teixeira Closs** \\ Graziela Scheffer Machado*** \\ Inez Rocha Zacarias****
}

\section{Resumo:}

O artigo apresenta resultados de estudo sobre as relações de gênero nas trajetórias das pioneiras do Serviço Social, a partir da análise de depoimentos de assistentes sociais que constituíram cursos de Serviço Social nos estados do Rio de Janeiro e Pernambuco. Objetiva analisar como as referidas relações se expressam nas trajetórias de vida e de trabalho destas pioneiras, considerando o contexto histórico, social e cultural no qual estão inseridas. As pioneiras foram em sua maioria mulheres de classes médias e altas com valores cristãos, cuja inserção no mercado de trabalho foi motivada pela manutenção do status social e econômico, dada a condição de assalariamento como elemento determinante do vínculo com o Serviço Social. Apesar da incidência do conservadorismo nas suas experiências profissionais, construíram trajetórias de vida e de trabalho que apresentaram inflexões quanto aos papéis de gênero fixados na sociedade do seu tempo.

Palavras-Chave: Pioneiras; Serviço Social; Gênero; Fundamentos; Memória histórica.

\begin{abstract}
:
The article shows results of a study on gender relations in the trajectories of the pioneers of Social Work, based on the analysis of testimonies from social workers who constituted Social Work courses in the states of Rio de Janeiro and Pernambuco. The goal is to analyze how these relationships are expressed in the life and work trajectories of these pioneers, considering the historical, social and cultural context in which they are inserted. The pioneers were mostly women of middle and upper classes with christian values, whose insertion in the job market was motivated by the maintenance of social and economic status, given the condition of wage earning as a determining element of the link with Social Work. Despite the incidence of conservatism in their professional experiences, both lives and work trajectories presented inflections regarding the gender roles in the society of their time.
\end{abstract}

Key words: Pioneers; Social Work; Gender; Fundamentals; Historical memory

\footnotetext{
* Bolsista de Iniciação Científica PROBIC/FAPERGS. Graduanda em Bacharelado em Serviço Social.

** Doutora em Serviço Social (PUCRS). Professora Adjunta do Curso de Serviço Social da Universidade Federal do Rio Grande do Sul. Porto Alegre - Rio Grande do Sul - Brasil.

*** Doutora em Serviço Social (UFRJ). Professora Adjunta do Departamento de Fundamentos do Serviço Social na Faculdade de Serviço Social da Universidade do Estado do Rio de Janeiro

**** Doutora em Serviço Social (PUCRS). Professora Adjunta do Departamento de Serviço Social da Universidade Federal de Santa Catarina
} 


\section{Introdução}

O artigo apresenta resultados de pesquisa sobre as relações de gênero na trajetória das pioneiras do Serviço Social. Consideram-se pioneiras aquelas mulheres presentes na constituição das Escolas de Serviço Social, nas décadas de 1930 a 1950 . O material aborda como se expressam as relações de gênero nas suas trajetórias, na interface com o contexto social, tendo como base o materialismo histórico-dialético para a análise da realidade, considerando as suas trajetórias no movimento da história. Ou seja, trata-se de uma abordagem histórica que visa apreender o Serviço Social numa perspectiva de totalidade, considerando sua gênese e seu desenvolvimento, suas agências de formação, suas práticas, seus sujeitos, seus sistemas de saber e seus valores na articulação com o quadro sóciohistórico e cultural em que se insere a profissão (ESCORSIM NETTO, 2011).

Nessa ótica, a angulação para as relações de gênero no percurso da profissão consiste numa potencialidade de adensamento da pesquisa sobre os Fundamentos do Serviço Social, considerando sua marca feminina na divisão sociotécnica e sexual do trabalho, temática parcamente explorada na produção da área, especialmente no que se refere à recuperação de memórias profissionais. Como destaca Netto (2011, p. 88), trata-se de um

[...] campo de pesquisa em aberto, e potencialmente promissor, aquele que aponta para as relações entre a profissionalização do Serviço Social e os movimentos específicos das mulheres. Sem projetar para o passado questões que só recentemente ganharam notoriedade, parece-me válida a hipótese de que, pela via da profissionalização no Serviço Social, contingentes femininos conquistaram papéis sociais e cívicos que, fora desta alternativa, não lhes seriam acessíveis.

Nesse horizonte, foram analisados sete depoimentos ${ }^{1}$ de assistentes sociais que atuaram na constituição de escolas de Serviço Social do Rio de Janeiro, de Niterói e de Recife. A pesquisa, de enfoque qualitativo, possibilitou uma aproximação com as suas experiências sociais, ao captar a singularidade dessas trajetórias a partir de seu pertencimento a uma referência grupal, expressando as vivências de dado segmento social (MARTINELLI, 1999). Destaca-se o caráter subjetivo mas também social da memória, pois o que se busca no passado é algo que se interpõe no presente como questão a ser desvendada e recuperada.

\footnotetext{
1 As entrevistas analisadas integram o banco de dados do Centro de Pesquisa e Documentação de História Contemporânea do Brasil (CPDOC), da Fundação Getúlio Vargas (FGV) e foram coletadas para o projeto "Memória da assistência social no Brasil: constituição de banco de entrevistas".
} 
A partir de revisão bibliográfica da literatura em Fundamentos do Serviço Social ${ }^{2}$ e de gênero ${ }^{3}$, foram elencadas as seguintes categorias para a análise de conteúdo (BARDIN, 2016), com vistas à caracterização do perfil das pioneiras: as relações familiares, abarcando suas origens de classe e herança cultural; a religiosidade, considerando essa influência na sua inserção educacional, na profissionalização em Serviço Social e na esfera dos valores; o casamento, enquanto elemento central na organização da vida das mulheres da época; e o trabalho, englobando as motivações pessoais e as condições objetivas para o exercício da profissão.

O artigo apresenta inicialmente uma breve revisão teórica, com ênfase para os Fundamentos do Serviço Social e para a constituição dos primeiros cursos do país, de forma a situar o contexto histórico das trajetórias profissionais analisadas nos depoimentos, tecendo mediações desse debate com as relações de gênero. A partir desses pressupostos são sistematizados dados sobre o perfil das pioneiras do Serviço Social, recuperando sua memória e experiências profissionais. Por fim, apresentam-se considerações acerca dos principais achados deste estudo.

\section{Fundamentos do Serviço Social e relações de gênero}

Parte-se da premissa de que a relação indissociável entre história/teoria/método é constitutiva dos Fundamentos do Serviço Social, a qual "(...) diz respeito à explicação do Serviço Social - de seu processo de constituição e desenvolvimento - no quadro das relações entre Estado e sociedade, em suas relações com o mundo do trabalho, com a trama do poder e com o universo da cultura" (IAMAMOTO, 2013, p. 190). Portanto, trata-se de superar o endogenismo, uma vez que "a profissão e o conhecimento que a ilumina se explicam no movimento histórico da sociedade" (YAZBEK, 2009, p. 144). Como aponta lamamoto (2011, p. 175), o Serviço Social "surge como um tipo de especialização do trabalho na sociedade que carrega em si um suposto de explicação da vida social como base para a ação, para a intervenção no processo social".

\footnotetext{
2 Destacam-se as seguintes referências: Castro (2011), Closs (2015), lamamoto (2011, 2013), lamamoto \& Carvalho (2014), Netto (2011), Machado, (2015), Yazbek (2009).

3 Destacam-se as seguintes referências: Cisne (2012), Cisne \& Santos (2018), Saffioti (2015), Davis (2016), Gonzalez (2020).
} 
Nessa perspectiva, entende-se os Fundamentos do Serviço Social (CLOSS, 2015) consistem "na forma particular na qual a profissão constitui uma matriz explicativa da realidade e da profissão, gestada no movimento histórico da sociedade" (p. 38) , a qual consiste num campo de mediações "engendrado na interseção entre as matrizes do pensamento social e a realidade sócio-histórica em que se inscreve como uma especialização do trabalho" (p. 39), articulando "dimensões teórico-metodológicas - que fornecem as bases explicativas da compreensão da realidade, da profissão, dos processos societários - e dimensões ético-políticas, condensadas na direção social da profissão, nos valores e compromissos que orientam a intervenção na realidade" (p. 38). Além disso, o vínculo orgânico do Serviço Social com a questão social é dimensão central aos Fundamentos, pois aporta elementos analíticos que se desdobram no debate da gênese profissional e da natureza e inscrição particular da profissão na sociabilidade burguesa e na divisão sociotécnica do trabalho (IAMAMOTO; CARVALHO, 2014; NETTO, 2011).

Destaca-se que a legitimação e o reconhecimento social da profissão são marcados pela sua feminização, enquanto "um processo histórico-cultural de construção de práticas, saberes e valores em relação ao feminino" (CISNE, 2012, p. 44). Portanto, a articulação dialética entre os Fundamentos e as relações de gênero é indispensável para a análise sóciohistórica da profissão e, no debate em tela, para situar o protagonismo das pioneiras do Serviço Social face os papéis de gênero de seu tempo histórico.

Parte-se da compreensão de Saffioti (2015) de que o gênero ${ }^{4}$ consiste numa categoria analítica e histórica, comportando diferentes interpretações. No entanto, é consenso que "o gênero é a construção social do masculino e do feminino", ainda que o conceito não explicite a desigualdade entre os homens e as mulheres. Portanto, "muitas vezes a hierarquia é apenas presumida" (SAFFIOTI, 2015, p. 47) e, para garantir a criticidade do conceito de gênero, ele deve estar articulado ao patriarcado. O patriarcado possui base material e histórica, consiste num "regime da dominação-exploração de mulheres pelos homens" (SAFFIOTI, 2015, p. 47). Numa perspectiva de totalidade, Saffioti (2015) demarca que "o patriarcado (...), enovelado com as classes sociais e o racismo, apresenta não apenas uma hierarquia entre as categorias

\footnotetext{
${ }^{4}$ Há um movimento recente no Serviço Social na defesa da terminologia relações sociais de sexo em substituição ao conceito de gênero (CISNE \& SANTOS, 2018). No entanto, a intenção deste artigo não é a de aprofundar uma discussão teórica sobre o tema, e o uso de gênero, aliado ao conceito de patriarcado e divisão sexual do trabalho, garante como uma perspectiva crítica do conceito e subsidia a análise histórica da profissão.
} 
de sexo, mas traz também, em seu bojo, uma contradição de interesses." (p. 113). Ou seja, "não se trata de somar racismo + gênero + classe social, mas de perceber a realidade compósita e nova que resulta desta fusão." (SAFFIOTI, 2015, p. 122).

Assim, os papéis de gênero dizem respeito às expectativas sociais quanto ao comportamento de homens e mulheres, os quais são construtos históricos, em suas determinações sócio-econômicas e culturais no âmbito da sociabilidade burguesa. Tais papéis estão ligados a concepções essencialistas e biologizantes da mulher - como a compreensão de que ela é naturalmente cuidadosa, maternal e emocional -, mas também de que os homens são naturalmente mais fortes, inteligentes e racionais. Mediando essa abordagem na análise da profissão, trabalha-se com a hipótese de que as trajetórias das pioneiras apresentam inflexões nos papéis de gênero estabelecidos na sociabilidade de seu tempo. Apesar de terem exercido uma profissão considerada feminina - com sua gênese associada à caridade e ao cuidado, atendendo aos interesses do Estado e da Igreja Católica - elas protagonizaram feitos que transcendem às expectativas para o seu gênero, como evidenciam os dados obtidos nos depoimentos, referentes às suas experiências profissionais.

A partir desses pressupostos é que tematiza-se a incidência das relações de gênero nas trajetórias das pioneiras do Serviço Social, considerando a sua inscrição na sociedade de seu tempo, face às tendências de institucionalização da profissão, processo diretamente relacionado à constituição dos primeiros cursos. As pioneiras, cujos depoimentos foram analisados, vincularam-se à implantação de três escolas de Serviço Social: o Instituto de Educação Familiar e Social (IEFS/RJ), criado em 1937, no Rio de Janeiro ( Maria da Glória Lisboa Ferreira, Aylda Pereira Reis e Maria de Lourdes Almeida de Moraes ${ }^{5}$ ); a Escola de Serviço Social de Recife (ESSR/PE), criada em 1940 (Anita Aline Albuquerque Costa e Evany Gomes de Matos Mendonça); e a Escola de Serviço Social de Niterói (ESSN/RJ), constituída em 1945 (Nilda de Oliveira Ney de Vasconcellos Cruz e Violeta Campofiorito Saldanha da Gama).

Nesse horizonte, a criação das primeiras escolas no Brasil "revela momentos específicos de um processo de maturação que atinge um ponto qualitativamente novo, quando a profissão começa a se colocar sua própria reprodução de modo mais sistemático" (CASTRO, 2011, p. 35). Como analisa Netto (2011), o fundamento objetivo da

\footnotetext{
${ }^{5}$ Iniciou o curso de Serviço Social na Escola de Serviço Social de Recife em 1940 e se formou no Instituto de Educação Familiar e Social, retornando a Recife para dirigir a Escola de Serviço Social.
} 
profissionalização do Serviço Social situa-se nas condições históricas da ordem monopólica que engendram a demanda objetiva para a emersão desta profissão na divisão sociotécnica do trabalho, ordem marcada pelo traço intervencionista do Estado junto à questão social, mediante as políticas sociais. Trata-se, portanto, da apreensão da gênese e do desenvolvimento da profissão frente à questão social, da emersão política da classe operária no cenário brasileiro exigindo o seu reconhecimento pelo Estado, delineando um papel particular para o Serviço Social enquanto mecanismo das classes dominantes (IAMAMOTO, CARVALHO, 2014). Nesse contexto,

\begin{abstract}
Terá particular importância na estruturação do perfil da emergente da profissão no país, a Igreja Católica, responsável pelo ideário, pelos conteúdos e pelo processo de formação dos primeiros assistentes sociais brasileiros. As primeiras iniciativas de organização da profissão são conduzidas por grupos sociais majoritariamente femininos, integrantes do movimento católico leigo e responsáveis pela ação social da Igreja Católica junto aos segmentos mais vulnerabilizados e empobrecidos da classe trabalhadora, especialmente mulheres e crianças (YAZBEK, MARTINELLI, RAICHELIS, 2008, p. 8)
\end{abstract}

A emergência da profissão articula-se com as estratégias da Igreja de qualificação do laicato, em especial na sua parcela feminina, via movimentos de Ação Social e Ação Católica. O Serviço Social buscou na doutrina social católica suas fontes de justificação ideológica, com forte incidência do Serviço Social europeu, incorporando o posicionamento reformista da Igreja frente à questão social, o qual consistia numa visão cristã corporativa para o desenvolvimento harmônico da sociedade, uma terceira via antiliberal e antissocialista (CASTRO, 2011). Importa destacar a incidência das relações de gênero nesse processo, pois as pioneiras da profissão,

(...) aceitando a idealização de sua classe sobre a vocação natural da mulher para as tarefas educativas e caridosas, desenvolveram uma intervenção que assumia, aos olhos dessas ativistas, a consciência do posto que cabe à mulher na preservação da ordem moral e social e o dever de tornarem-se aptas para agir de acordo com suas convicções e suas responsabilidades. Incapazes de romper com essas representações, o apostolado social permite àquelas mulheres, a partir da reificação daquelas qualidades, uma participação ativa no empreendimento político e ideológico de sua classe, e da defesa de seus interesses. Paralelamente, sua posição de classe lhes faculta um sentimento de superioridade e tutela em relação ao proletariado, que legitima a intervenção. (IAMAMOTO; CARVALHO, 2014, p. 182-183).

Como amplamente debatido (IAMAMOTO; CARVALHO, 2014), a primeira escola brasileira foi criada em São Paulo tendo como antecedentes o Centro de Estudos e Ação Social, 
o qual objetivava a difusão da doutrina da Igreja Católica. Diferentemente de São Paulo, no Rio de Janeiro há uma participação mais intensa das instituições públicas na criação das Escolas de Serviço Social, com o apoio da alta administração federal, da cúpula hierárquica da Igreja e do movimento católico laico. A necessidade de uma formação especializada na área social não foi exclusiva ao movimento católico, sendo também uma demanda posta ao Estado e ao empresariado, unificando esforços desses segmentos com a Igreja Católica em ações voltadas ao "reerguimento" das classes trabalhadoras (IAMAMOTO; CARVALHO, 2014). Nessa dinâmica, destaca-se que a atuação estatal impulsionou a profissionalização do assistente social em função das novas formas de enfrentamento da questão social, pela via das políticas sociais (YAZBEK; MARTINELLI; RAICHELIS, 2008).

Quanto às escolas cariocas, o Instituto de Educação Familiar e Social (IEFS) foi criado em 1937, por iniciativa de grupo vinculado à Ação Social, com o apoio governamental. Apesar desse apoio, destaca-se a forte marca católica na sua constituição, que incidirá no perfil das primeiras gerações da escola, como aponta o depoimento de uma das suas docentes pioneiras.

Preferencialmente, eram moças de boa família, de classe média, de um bom nível. Todas tinham uma formação anterior, segundo o julgamento delas, adequada ao Serviço Social. De um modo geral, todas eram normalistas. Elas faziam muita questão de uma boa base, sabe? Faziam questão de um bom nível. Eram poucas porque a seleção era muito rigorosa e depois o curso era muito rigoroso. (REIS, 2002, p. 9).

Destaca-se que a constituição da Escola Técnica de Assistência Social Cecy Dodsworth, em 1944, possui bases sócio-políticas distintas, especialmente pelo maior impulso estatal, o que incidiu no perfil das pioneiras. Seus antecedentes situam-se no curso intensivo de Serviço Social promovido em 1938 pelo Juizado de Menores em parceria com a Instituição S.O.S de atendimento à infância pobre, organizado por Maria Esolina Pinheiro (MACHADO, 2015). Conforme documento histórico ${ }^{6}$, as 48 formadas constituíram o Serviço Social SOS no RJ, sob direção de Terezita Porto da Silveira.

A Escola de Serviço Social de Niterói (ESSN) foi constituída em 1945 mediante apoio da Legião Brasileira de Assistência (LBA), sendo reconhecida como instituição de nível superior em 1956, e integrada à Universidade Federal Fluminense na década de 1960. A sua criação

\footnotetext{
6 "Serviço Social: Síntese histórica do Distrito Federal e Estado do Rio. Contribuição da Assistente Social Maria Esolina Pinheiro (ABESS, s/d), acervo histórico UERJ (MACHADO, 2015).
} 
relaciona-se com o processo de ampliação das grandes instituições assistenciais e patronais, com a expansão da assistência social sob as marcas do clientelismo e do primeiro-damismo (IAMAMOTO; CARVALHO, 2014). Alzira Vargas - então primeira-dama - participou da LBA local e, posteriormente, da fundação da ESSN, protagonizando iniciativas de aperfeiçoamento técnico necessárias à atuação nos serviços sociais em estruturação, mobilizando pioneiras de outras escolas, conforme relata Nilda Cruz.

A escola pertencia ao estado e à LBA, meio a meio. A LBA, primeiro, tinha um curso de visitadoras. Depois dona Alzira fundou a escola. Entre essas visitadoras estavam Inaiá Moraes, Violeta Saldanha da Gama, que depois foi minha aluna, e elas fundaram a escola. E depois, a diretora da escola do Rio, Maria Isolina Pinheiro, fez parte da comissão. (CRUZ, 2002, p. 11).

Algumas particularidades da ESSN a diferenciam dos demais cursos cariocas, quais sejam (FREITAS; BARROS, 2009): a manutenção compartilhada entre LBA e Estado, a inexistência de mensalidade e, o perfil das alunas, pois o curso era frequentado não somente por moças da "alta sociedade", mas também por professoras primárias que recebiam integralmente seus salários para se dedicarem aos estudos.

As relações entre segmentos católicos e organizações estatais também incidiram na criação dos cursos de Serviço Social do Nordeste, tal como a de Recife, constituída em 1940, com o protagonismo de Rodolfo Aureliano - Juiz de Menores e católico. Em 1941 a Escola foi tornada de interesse público sendo mantida por subvenções estatais e pelas mensalidades das alunas (VIEIRA, 2008). Para a sua consolidação, a Escola enviou duas alunas - Maria Dolores Coelho e Maria de Lourdes Moraes - ao IEFS no Rio de Janeiro. Ao retornarem, assumiram a condução da Escola de Serviço Social de Recife. Sobre esse intercâmbio, Aylda Reis relata que

\footnotetext{
A Lourdes foi minha aluna. Aconteceu isso também: foram sendo abertas outras Escolas e o último ano das Escolas dos estados era feito aqui no Rio de Janeiro. A LBA proporcionou bolsas de estudo para as primeiras turmas dos estados. E como nesse tempo eu já era professora, todas que vieram dos estados foram minhas alunas." (REIS, 2002, p. 10-11).
}

Sobre as tendências de formação em Recife, uma de suas pioneiras refere que "todo o pessoal da Escola, do princípio da Escola, era cristão. Não posso dizer que fosse católico propriamente. Nós tínhamos um ideal de seriedade, de honestidade." (MORAES, 2002, p. 6). Já outro depoimento destaca que, apesar da influência católica, no entanto, essa poderia ser considerada uma escola "leiga". 


\begin{abstract}
A Igreja teve uma importância enorme no Serviço Social em Pernambuco, não sentíamos muito isso. A única escola leiga em todo o Norte e Nordeste foi a de Recife! Ela nasceu pela mão de um 'catolicão', está certo, mas um juiz de menores, não foi pela mão da Igreja. Mas se considerarmos Alagoas, Paraíba, Ceará, Maranhão, Bahia... todas foram missionárias! (COSTA, 2002, p. 16).
\end{abstract}

Em síntese, verifica-se que as primeiras escolas de Serviço Social, apesar de apresentarem particularidades no seu processo de constituição, foram protagonizadas por segmentos vinculados à Igreja Católica e a organismos estatais. Embora algumas dessas escolas possuíssem tendências laicas e estatais, seus primeiros quadros foram fortemente influenciados pelo ideário católico e pelos papéis de gênero nas décadas de 1940 e 1950, o que imprimiu importantes mediações sócio-históricas no desenvolvimento da profissão. Dentre tais mediações (IAMAMOTO; CARVALHO, 2014), destaca-se o "imbricamento da teoria e metodologia do Serviço Social com a doutrina da Igreja e com o apostolado social" (p.231), cujo traço mais saliente consiste na substituição da "análise da realidade e prática social para o enfrentamento da questão social por valores, exigências, isto é, por uma apreensão moral dos fenômenos sociais" (p. 243). Dessa forma, o exercício do Serviço Social é visto como uma vocação - tendência relacionada às concepções essencializantes sobre as mulheres à época -, e embasado num humanismo cristão que não apreende as bases materiais da realidade, construindo-se certa mística em torno da profissão - "os modernos agentes da caridade e da justiça social" (IAMAMOTO; CARVALHO, 2014, p. 246), cujas características e perfis serão abordadas a seguir.

\title{
O perfil das pioneiras do Serviço Social
}

As pioneiras do Serviço Social construíram trajetórias de vida que extrapolaram os padrões vigentes para mulheres de suas origens social, econômica e de gênero. Para compreender a complexidade de seus percursos é imprescindível vislumbrar o panorama sócio-histórico repleto de contradições que condicionaram suas vidas.

Destaca-se que embora as pioneiras tenham protagonizado realizações significativas para o seu tempo, suas trajetórias profissionais são tecidas sob a influência do 
conservadorismo ${ }^{7}$, o qual é restaurador e preservador da autoridade moral (YAZBEK, 2009). Dentre as características do pensamento conservador, destacam-se (IAMAMOTO, 2013): a vocação para um modo de vida do passado, baseado na tradição, na autoridade e nos costumes; a compreensão da sociedade em entidades orgânicas articuladas, tendo a família como modelo; a valorização da individualidade e a compreensão da liberdade restrita à vida privada e subordinada aos princípios da ordem nas relações externas. Como destacam lamamoto e Carvalho (2014), o autoritarismo, o doutrinarismo e a ausência de base técnica que marcam os primeiros núcleos profissionais são frequentemente atribuídos à influência europeia ${ }^{8}$ na constituição dos primeiros cursos, mas esses traços não são mera transposição de concepções externas à realidade brasileira. A assimilação das referidas características refletem a ideologia da classe dominante brasileira que constitui o bloco católico brasileiro nas décadas de 1930 a 1940.

Da segunda metade do século XIX até as primeiras décadas do século XX há uma crescente expressão de manifestações de mulheres por direitos políticos no Brasil. (PINTO, 2003). No período em que as pioneiras ingressaram no mercado de trabalho, em meados da década de 1940, há um esvaziamento das discussões concernentes ao feminismo no Brasil. Nos anos 1950 há um fortalecimento da valorização da família, do lar e da mulher enquanto mãe e cuidadora, tendência que configurou-se como uma resposta conservadora aos avanços conquistados, como o sufrágio feminino em 1932 e a crescente participação da mulher nos espaços públicos, como o da política e da imprensa, ainda que em quantidade inexpressiva quando comparada ao universo de mulheres no país. Outra contradição da inserção da mulher branca e de classe média ${ }^{9}$ no mercado de trabalho foi a de que a conquista de sua participação em espaços públicos foi acompanhada pela crescente utilização de argumentos essencializantes e biologizantes que aprisionavam as mulheres à condição de mãe e cuidadora.

Parte-se desse contexto histórico para apreender o perfil das pioneiras, compreendendo que seus depoimentos revelam experiências sociais representativas de dado

\footnotetext{
7 Considerando os limites expositivos deste artigo, para o aprofundamento do debate do conservadorismo clássico ver Escorsim Netto (2011).

8 Para uma caracterização do Serviço Social europeu em suas origens ver Martinelli (2003), tendo em vista a incidência do mesmo nas primeiras escolas brasileiras.

${ }^{9} \mathrm{O}$ ingresso no mercado de trabalho é uma conquista para um setor específico das mulheres - as brancas de classe média - já que as mulheres da classe trabalhadora e negras escravizadas já trabalhavam. Nesse sentido, ver Davis (2016) e Gonzalez (2020).
} 
segmento social, expressando tendências postas na realidade quanto à presença feminina no espaço público. Nessa perspectiva, faz-se necessária uma leitura de suas experiências profissionais que supere a perspectiva de que

[...] essas mulheres são olhadas com o olhar do presente e condenadas por um conservadorismo que na realidade não as caracterizou. Ou melhor, que não as caracteriza unicamente. [...] Elas ousaram sair do "círculo restrito traçado a sua volta". Elas foram muito mais longe. Mas - e isso é fundamental não esquecermos são mulheres "comuns", são pessoas comuns como qualquer um(a) de nós. E, principalmente, são mulheres do seu tempo. (FREITAS; BARROS, 2009, p. 62).

Assim, o estudo do perfil das pioneiras foi desenvolvido a partir das categorias de origem, da religiosidade, da educação, do casamento e do trabalho, tendo como corpus de análise o conteúdo de sete entrevistas realizadas pelo Centro de Pesquisa e Documentação de História Contemporânea do Brasil da Fundação Getúlio Vargas, integrantes do Projeto "Memória da Assistência Social no Brasil: constituição de banco de entrevistas com as assistentes sociais". A sistematização do perfil das pioneiras - articulando dados das entrevistas e revisão bibliográfica - busca explicitar que as suas experiências de vida e trabalho não se constituem como fenômenos isolados, mas sim evidenciam a inserção das mulheres na sociedade de sua época, revelando tendências sobre a profissão em sua interface com os papéis de gênero. Considerando as subjetividades das pioneiras inscritas no âmbito da (re) produção das relações sociais entende-se que

A produção da consciência tem seu fundamento na prática da vida social tal como ela se configura, historicamente. Expressa a maneira como a dinâmica social vem sendo apreendida pelos diversos agentes sociais, em dados momentos históricos. Não se trata, pois, de uma representação única e homogênea para todas as personagens sociais, enquanto portadoras de diversos interesses de classe. (IAMAMOTO; CARVALHO, 2014, p.117)

Nessa perspectiva, o quadro a seguir apresenta uma síntese das informações nos depoimentos, dando visibilidade para as trajetórias profissionais das pioneiras, para na sequência serem abordados elementos da caracterização do seu perfil.

Quadro 1: Caracterização das trajetórias profissionais das pioneiras do Serviço Social

\begin{tabular}{|c|c|}
\hline $\begin{array}{c}\text { Nome e Escola de } \\
\text { Serviço Social }\end{array}$ & Síntese das trajetórias profissionais \\
\hline $\begin{array}{c}\text { Maria da Glória } \\
\text { Lisboa Ferreira }\end{array}$ & $\begin{array}{c}\text { Nascida em 08/05/1916 em Petrópolis. Trabalhou na Imprensa Nacional de 1941 a 1944. Alistou- } \\
\text { se atuou na UNRRA/ONU na Alemanha de 1945 a 1952. Docente na Escola de Serviço Social no } \\
\text { IEFS em 1952. Estudou nos EUA e Canadá com bolsa da ONU em 1955 ou 1956. Trabalhou na }\end{array}$ \\
\hline
\end{tabular}




\begin{tabular}{|c|c|}
\hline (IEFS/RJ) & $\begin{array}{l}\text { Comissão Brasileira de Imigração com Dom Helder Câmara por } 15 \text { anos. Docente de Sociologia } \\
\text { da Universidade Brasil em } 1960 .\end{array}$ \\
\hline $\begin{array}{l}\text { Aylda Pereira Reis } \\
\text { (IEFS/RJ) }\end{array}$ & $\begin{array}{l}\text { Nascida em 25/09/1912 em Porto Alegre. Formou-se na Escola Normal. Formou-se no IEFS em } \\
\text { 1941. Organizou o curso de Serviço Social na Escola Ana Nery em 1941. Diretora do IEFS de } 1946 \\
\text { e 1950. Docente no IEFS. Trabalhou na Missão de Itaperuna de } 1950 \text { a 1952. Realizou trabalho } \\
\text { voluntário na CNBB por } 5 \text { anos. Trabalhou na União Panamericana, na Venezuela em } 1958 .\end{array}$ \\
\hline $\begin{array}{l}\text { Maria de Lourdes } \\
\text { Almeida de Moraes } \\
\text { (IEFS/RJ, ESSR/PE) }\end{array}$ & $\begin{array}{l}\text { Nascida em 08/07/1914 em Olinda/PE. Formou-se na Escola Normal. Inicia o curso de Serviço } \\
\text { Social em Recife em 1940, mas é enviada para concluir o curso no IEFS no Rio de Janeiro, onde } \\
\text { forma-se em } 1942 \text { ou 1943. Diretora da ESSR em } 1942 \text { ou } 1943 \text { por } 18 \text { anos. Docente na ESSR. } \\
\text { Estudou na Bélgica após se formar. }\end{array}$ \\
\hline $\begin{array}{l}\text { Anita Aline } \\
\text { Albuquerque Costa } \\
\quad \text { (ESSR/PE) }\end{array}$ & $\begin{array}{c}\text { Formou-se na Escola Normal. Formou-se em curso de nutrição no Rio de Janeiro de } 1949 \text { a } 1951 . \\
\text { Iniciou o curso de Serviço Social na ESSR em 1950. Retornou ao curso em } 1958 \text { e formou-se em } \\
\text { 1962. Trabalhou no Juizado de Menores, na Merenda Escolar da Secretaria de Educação, na LBA } \\
\text { e na FEBEM. Docente na ESSR em 1962. Realizou curso de aperfeiçoamento para professores da } \\
\text { ABESS em } 1966 \text { no RJ. Fez mestrado na PUCSP de } 1973 \text { a 1977. Chefiou o Departamento de } \\
\text { Serviço Social entre } 1976 \text { e } 1980 \text { da Universidade Federal de Pernambuco. Fez doutorado na } \\
\text { PUCSP de } 1986 \text { a } 1991 .\end{array}$ \\
\hline $\begin{array}{l}\text { Evany Gomes de } \\
\text { Matos Mendonça } \\
\text { (ESSR/PE) }\end{array}$ & $\begin{array}{l}\text { Nascida em Sertânia/PE. Formou-se na Escola Normal em Recife em 1940. Formou-se na ESSR } \\
\text { em 1956. Foi professora (normalista) e de Educação Física, através de concurso estadual. } \\
\text { Trabalhou no SESI de } 1946 \text { a 1948. Vice-diretora da ESSR em 1956. Docente na ESSR desde } 1956 . \\
\text { Diretora da ESSR de } 1961 \text { a 1971. Estudou no curso da USAID, nos EUA em 1966. Fez estágio no } \\
\text { Chile em 1969. Fez mestrado na PUCRJ de } 1972 \text { a 1978. Trabalhou no Ministério da Saúde em } \\
\text { parceria com a UNICEF. }\end{array}$ \\
\hline $\begin{array}{l}\text { Nilda de Oliveira Ney } \\
\text { de Vasconcellos Cruz } \\
\text { (ESSN/RJ) }\end{array}$ & $\begin{array}{l}\text { Nascida em 18/09/1916 em Santo Antônio de Pádua/RJ. Formou-se na Escola NormaL em } 1932 . \\
\text { Trabalhou como professora desde 1932. Formou-se na ESSN. Fez } 9 \text { especializações na } \\
\text { Universidade Rural entre } 1942 \text { e 1943. Trabalhou na Campanha Nacional Contra a Tuberculose } \\
\text { desde 1949. Chefiou a Superintendência de Serviço Social dessa Campanha de } 1956 \text { a } 1969 . \\
\text { Docente na ESSN. Vice-Diretora da ESSN. Diretora da ESSN por duas gestões. Foi ao Chile } \\
\text { conhecer duas Escolas de Serviço Social em 1950. Fez curso de verão na Escola de Buenos Aires } \\
\text { em 1952. Fez mestrado nos EUA de } 1956 \text { a 1958. Diretora da ABESS por duas gestões. }\end{array}$ \\
\hline $\begin{array}{l}\text { Violeta Campofiorito } \\
\text { Saldanha da Gama } \\
\quad \text { (ESSN/RJ) }\end{array}$ & $\begin{array}{c}\text { Nascida em 03/10/1909 em Belém do Pará. Formou-se na Escola Normal em 1928. Foi } \\
\text { professora desde 1924. Formou-se na Escola Nacional de Belas Artes em 1939. Foi professora de } \\
\text { desenho na Escola Industrial Henrique Lages. Formou-se na ESSN em 1951. Foi Chefe do Serviço } \\
\text { Social de Obras da LBA por } 20 \text { anos. Diretora da ESSN em 1951. Docente da ESSN. Foi tesoureira } \\
\text { da ABESS. Estudou no Centro Internacional da Criança em Paris. Foi à Argentina observar o curso } \\
\text { para moças de Eva Perón. Fez o curso Educação para o Serviço Social nos EUA, junto a } 7 \text { diretoras } \\
\text { de Escolas de Serviço Social e discursou na ONU. Fez curso sobre Desfavelização nos EUA em } \\
1963 .\end{array}$ \\
\hline
\end{tabular}

Fonte: Sistematização das autoras a partir do banco de dados das entrevistas.

As pioneiras integraram a primeira geração de mulheres de suas famílias a exercer atividade laborativa remunerada. Essa inflexão explica-se a partir de alterações na sociedade brasileira, com incidência na esfera econômica de setores de classe média e alta, uma vez que os depoimentos evidenciam que a maioria exerceu atividade remunerada a fim de manter o nível sócio-econômico do seu grupo familiar. A formação educacional profissional e a atividade laborativa tornaram-se paulatinamente mais aceitas para as jovens mulheres, desde que consideradas uma extensão do "lar", com tarefas que estivessem ligadas à concepção 
essencialista de mulher e enaltecedora da maternidade, tais como lecionar, cuidar, curar e assistir. Processo que não é unilateral, pois "a profissão, mesmo com enlaces conservadores na questão da mulher - via Igreja e família -, proporcionou às pioneiras que traçassem uma estratégia para sua própria liberdade" (MACHADO, 2015, p. 306).

Destaca-se que as genitoras das pioneiras permaneceram relegadas ao lar e desempenhando atividades domésticas - trabalho desvalorizado e não pago, mas indispensável para a (re)produção social. Apesar de terem sido destinadas ao casamento e aos filhos, as mães das pioneiras tiveram acesso ao aprendizado de piano, francês e literatura como meio de acessar candidatos qualificados ao matrimônio pertencentes à classe social média e alta. Violeta Gama, num relato comum às pioneiras sobre suas origens familiares, evidencia mudanças nos papéis de gênero em relação às gerações anteriores: “Minha mãe só ficou tomando conta da casa, fazendo aos domingos reunião dos amigos e dos filhos. [...] Então, ficou dona de casa sempre. Faleceu até muito jovem, mas não tinha nenhum emprego" (GAMA, 2002, p. 2).

Sobre as motivações para exercer a profissão, a maioria das pioneiras ( 5 de 7 ) refere que a atividade remunerada visava contribuir com o sustento da família, sendo que somente uma não trabalhou antes de ingressar na Escola de Serviço Social (REIS, 2002). O depoimento de Violeta Gama expressa essa tendência, referindo "ter começado a dar aula por querer e por precisar".

Porque eu quis só não; eu quis também. Acontece que, naquela época, um arquiteto não tinha salário tão alto. Eram quatro filhos estudando, os meninos no Colégio Brasil, minha irmã na Escola Aurelino Leal e eu na Escola Normal. E todos gastando muito, morando bem, tendo uma vida regular e boa, porque mamãe agüentava uma vida muito boa para a família. Não era fácil naquela época, como não é agora e nunca foi. Então, eu precisava ganhar meu dinheirinho até para ajudar na merenda, nas coisas. Às vezes eu ia a pé para o Liceu, porque nem sempre a gente tinha dinheiro para pagar passagem. Tinha que fazer qualquer coisa, todos nós tínhamos um biquinho; era muito comum naquela época. (GAMA, 2002, p. 3)

Também ilustrando essa tendência, Anita Costa (2002, p. 3) refere que "estudei com dificuldade, trabalhando muito com os livros dos outros, e terminei o curso de professora com 17 anos". Os depoimentos revelam que a necessidade de trabalhar foi um dos fatores determinantes para que a maioria (6 de 7) tivessem cursado Escola Normal e atuado como professoras antes de serem assistentes sociais. Essas trajetórias guardam relação com as atividades laborativas ditas "femininas" nesse período, restritas e predominantemente 
relacionadas com as profissões dedicadas ao cuidado e ao ensino. Além disso, terem sido trabalhadoras da educação favoreceu o acesso à formação em Serviço Social, através da concessão de bolsas pelo Estado do Rio de Janeiro, como também identificado nos depoimentos.

Apesar de sua origem social, as entrevistas indicam que o trabalho em Serviço Social foi motivado por necessidades materiais, já que "o declínio econômico das famílias das pioneiras foi o fator determinante para sua inserção no mundo do trabalho, para colaborar no orçamento familiar." (MACHADO, 2015, p. 299). Ou seja, apesar de Serviço Social ter sido reconhecido como profissão liberal, sua inserção majoritária deste então ocorre em instituições públicas e privadas, caracterizando seu perfil assalariado, embora o forte vínculo com a Igreja, a valorização de qualidades morais e do "altruísmo" tenham jogado forte peso na obstrução da compreensão da relação mercantil que já presidia as suas relações de trabalho (YAZBEK; MARTINELLI; RAICHELIS, 2008).

No que tange à religiosidade, a maioria tinha filiação ao catolicismo (6 de 7) e, embora somente uma fosse oriunda de família vinculada a igreja batista, refere ter sido batizada pelo pai na Igreja Católica "para não ser considerada pagã" (CRUZ, 2002). No entanto, a minoria delas (2 de 7) atuava em movimentos da igreja, como exemplifica Maria Moraes $(2002$, p. 6) que, ao ser questionada, refere ter sido "da Ação Católica, fervorosa [riso]!", e que teria escolhido o Serviço Social "para servir, eu queria servir.". Já o depoimento de Anita Costa expressa outra tendência, ao referir que, apesar de católica, não mantinha uma relação orgânica com os movimentos da igreja.

Não, eu continuo católica, mas não sou piegas. Minha mãe sempre reagiu muito a isso também. Freqüento regularmente a igreja, tenho prática religiosa, mas discordo de uma porção de coisas da Igreja quanto à organização. Eu sempre procuro distinguir a organização da religião. A organização é uma coisa" (COSTA, 2002, p. 12).

As suas relações com a Igreja Católica estão intrinsecamente ligadas à perspectiva conservadora com a qual estavam alinhadas, ainda que nem sempre estivessem vinculadas à Ação Católica. O depoimento de Anita Costa demonstra a influência da religiosidade em suas trajetórias:

Acho que sempre fui conservadora. Não me intitulo como conservadora, mas tenho a impressão de que a educação no grupo familiar não me deu chance de me articular com um grupo de classe média alta, que eram os grupos que participavam da Ação Católica.(COSTA, 2002, p. 13). 
Enfatiza-se que, mesmo a partir dessas bases conservadoras e influências doutrinárias, as pioneiras do Serviço Social alçaram "voos" impressionantes para as mulheres de sua classe e de seu tempo. Esses "voos" ficam evidenciados em seus depoimentos, pois elas exerceram atividades laborativas remuneradas distantes de casa, sem o acompanhamento do pai ou do marido, feito incomum à época, bem como viajaram para o exterior desacompanhadas a fim de realizarem estudos de pós-graduação, num contexto em que a formação graduada ainda era restrita às mulheres. E ainda, alistaram-se para prestar serviços em outros países no pós II Guerra Mundial. Também exerceram a docência de nível superior e atuaram como diretoras de Escolas de Serviço Social, num contexto de pequena presença da mulher no espaço universitário.

Contudo, concomitantemente a estas conquistas, as suas atividades laborativas não constituíam-se como contraposições diretas ao machismo e ao conservadorismo justamente porque inseriram-se no âmbito dos papéis de gênero de seu contexto. Nilda Cruz (2002, p. 20), ao ser questionada se ser mulher se converteu em entraves para exercer a profissão em viagens durante a Campanha Nacional Contra a Tuberculose, destaca que "não, não teve nada! Nunca tive! É interessante, eu não senti nenhum preconceito não." Ou seja, essas mulheres cumpriram atividades extensivas ao lar - tais como o cuidar, educar e assistir -, tarefas ditas femininas e relacionadas à missão da Igreja Católica e às requisições do Estado nas respostas às expressões da questão social. Desse modo, por mais impressionantes que tenham sido os seus êxitos, suas experiências profissionais acompanham as limitações socialmente estabelecidas para a inserção das mulheres nos espaço públicos e na divisão sócio-técnica e sexual do trabalho de seu tempo.

Quanto ao estado civil das pioneiras, verifica-se que a maioria se casou (4 de 7), tendência recorrente no quadro das relações de gênero desse contexto. No entanto, o matrimônio não foi impeditivo para o exercício da profissão, pois a minoria cessou as atividades laborativas após o casamento, referindo exercer somente trabalho voluntário junto ao marido (REIS, 2002) ou, ainda, ter interrompido brevemente as atividades e após reingressar no mercado de trabalho por necessidade financeira, como menciona Anita Costa (2002, p. 11), relatando que "eu ia casar e deixar tudo, porque minha perspectiva era: eu não caso para trabalhar fora... Mas, sete anos depois de casada, eu voltei a trabalhar". 
Também por motivações econômicas, Violeta Gama (2002, p. 5) refere que, apesar das restrições de seu marido, continuou a trabalhar, comentando que "ele não gostava que a mulher trabalhasse fora, mas eu tinha que trabalhar, porque tudo era difícil naquela época. Então eu trabalhava mesmo, como professora primária, e depois fiz concurso". Registra-se, ainda, a menção à experiência de um casamento tardio para os padrões da época. Nilda Cruz $(2002$, p. 12) relata que o casamento não era sua prioridade, mas sim os estudos e o trabalho, referindo que "nunca tive namorado porque tive um plano de vida: estudar, fazer meu pé-demeia, ir para frente!". As demais pioneiras não relatam em suas entrevistas terem se casado ou ter tido filhos, sendo que uma delas descreve as perspectivas da sua família sobre relacionamentos afetivos.

Eu acho que formaram muito na minha cabeça, papai dizia assim: "Olha, uma moça pobre, que não tem dinheiro, cuidado com os homens porque eles querem somente para abusar, para não sei o quê e vão depois casar com outras que tenham mais possibilidades!" Então, aquela coisa foi crescendo muito na minha cabeça e eu não fui uma pessoa que lutei para isso não, entendeu? Eu fui beijar muito tardiamente. (MENDONÇA, 2002, p. 12).

A partir desse relato, Evany Mendonça (2002, p. 12) menciona suas percepções sobre o casamento, destacando que "só casar para ter uma casa, para ter um marido, isso não. Eu não tinha o menor interesse nesse tipo de coisa, de ir por aí. Então ficava mais complicado. $\mathrm{O}$ meu sonho era mais alto e acredito que minhas possibilidades eram muito grandes." Nessa perspectiva, Maria Ferreira, ao mencionar o contexto carioca à época da criação do Instituto de Educação Familiar e Social, aponta que o período era marcado pelo

[...] começo da evolução da mulher, quando a mulher deveria se preparar para trabalhar. Então, na sociedade em que eu vivia, de classe média e classe média alta, havia essa preocupação: como se preparar para essa evolução da mulher. Porque naquele tempo não se pensava em evolução, simplesmente em uma mudança qualquer na sociedade. Nós não podíamos prever a revolução que seria consequente da mulher ir trabalhar. (FERREIRA, 2002, p. 1)

As pioneiras refletiram o reformismo conservador (IAMAMOTO, 2011) de seu tempo, mas não se limitaram a ele. Apesar de suas concepções conservadoras sobre as relações de gênero, classe e raça, em especial junto ao público usuário dos espaços sócio-ocupacionais em que atuavam - combatendo os desajustamentos sociais e coletivos, pautadas na Doutrina Social da Igreja Católica -, as suas trajetórias de vida diferenciam-se das mulheres de sua época. Tais percursos foram possíveis, contraditoriamente, justamente por serem jovens "respeitosas" e "respeitadas" enquanto católicas, por exercerem uma profissão que era 
entendida como vocação e que manifestava uma resposta - ainda que não se resuma a isso à preocupação da Igreja Católica na reforma social da sociedade. Esta tendência se expressa nos objetivos de fundação do IEFS em 1937, conforme relato de uma de suas pioneiras.

\footnotetext{
Formar entre as mulheres, não de uma classe, mas de todas as classes sociais, uma consciência de comunidade cristã que venha substituir o individualismo liberal egoísta sem cair na socialização inumana e estatal. Para isso forma assistentes sociais, educadores familiares e donas de casa que venham ser no meio em que vivam e trabalham, nos institutos ou nos ambientes sociais em que atuam como elementos de correção de anomalias sociais, verdadeiros elementos de renovação pessoal e católica. (LIMA apud AGUIAR, 1995, p. 30).
}

Considerando o conjunto dos depoimentos, não é surpreendente que, ao serem questionadas sobre questões de gênero, as pioneiras demonstrassem uma opinião alinhada a de seu tempo, sem orientação feminista. Pelo contrário, quando Maria Moraes é questionada se "a senhora se classifica como uma feminista?", contesta que "ah, ih! Não me gusta. [riso]" (MORAES, 2002, p. 23-24). Este depoimento demonstra o quanto o seu pioneirismo está marcado pelo conservadorismo, ainda que sua atuação enquanto assistente social tenha tensionado, dentre os limites da ordem, os papéis de gênero do seu tempo.

\section{Considerações finais}

O artigo evidenciou a relevância da temática das relações de gênero para os Fundamentos do Serviço Social, considerando o período de institucionalização do Serviço Social e a inserção de uma profissão com a marca feminina na divisão sociotécnica e sexual do trabalho. Ao evidenciar o protagonismo das pioneiras face às tendências postas nas relações sociais quanto aos papéis da mulher na sociedade brasileira nas décadas de 1940 e 1950, ressaltou-se que elas foram em sua maioria mulheres oriundas das classes média e alta, influenciadas pelos valores cristãos. Casadas, conciliaram sua vida privada com o trabalho e com a inserção em espaços públicos, vivenciando novas experiências sociais face a geração que as antecedeu. Verificou-se que, apesar das mistificações do "altruísmo" e da "vocação", inseriram-se no mercado de trabalho para manutenção de um dado status social e econômico, sendo que maioria já exercia atividade remunerada antes da formação profissional. Em sua maioria, possuíam base educacional e cultural ampla para os padrões da época, realizaram formação em Escola Normal, eram católicas devotas, o que favoreceu sua inserção nas 
primeiras escolas de Serviço Social. Atendendo às expectativas sociais postas nas relações sociais para as mulheres brancas e pertencentes às classes médias e altas, exerceram atividades remuneradas voltadas ao assistir, educar e cuidar. Apesar do predomínio desse perfil profissional na emergência da profissão, aponta-se também o estudo de Scheffer (2016) sobre a trajetória da pioneira negra Dona Ivone Lara no trabalho junto à equipe de Nise da Silveira, o que evidencia a importância de novos estudos nessa área, dando visibilidade às diferentes tendências da profissão em sua fase de institucionalização.

Destaca-se que "as pioneiras não nasceram conservadoras, tornaram-se conservadoras, fruto histórico de sua época" (MACHADO, 2015, p. 304), ou seja, suas vidas foram permeadas pela influência de suas famílias, da religiosidade, dos papéis sociais que lhe eram atribuídos. Mas, apesar das marcas do conservadorismo, suas trajetórias apresentam inflexões no que tange aos papéis de gênero vigentes, já que aquilo que realizaram de excepcional para as mulheres de sua época e lugar social se construiu a partir de seu trabalho em uma profissão em consolidação, num quadro de recente inserção feminina no mercado de trabalho e nos espaços públicos.

Esse processo demonstra a relevância da atividade laboral em seu potencial libertador para a mulher, cujos impactos não se restringem à esfera privada, embora tal liberdade seja limitada nos marcos das relações de gênero do período em tela e pela sociabilidade capitalista, atravessada pelas nuances conservadoras da origem dessas pioneiras. Contudo, elas se diferenciam daquelas que permaneceram restritas ao lar, representando uma inflexão em termos da geração que as antecede, processo favorecido pelo envolvimento com o catolicismo e com o Serviço Social, o que permitiu irem além dos papéis fixados para as mulheres de seu tempo.

Parafraseando Marx (2011) - no que refere à relação dialética entre a ação dos sujeitos e as determinações históricas - as pioneiras "fizeram a sua própria história", "mas não a fizeram arbitrariamente, nas condições escolhidas" por elas, mas nas "condições dadas diretamente e herdadas pelo passado". Ou seja, trilharam, com protagonismo, os caminhos possíveis do trabalho no âmbito de profissões vinculadas ao educar, cuidar e assistir, trajetórias nas quais sentiram o peso da "tradição de todas as gerações" que "sobrecarrega o cérebro dos vivos", dadas as influências do conservadorismo e dos limites postos às mulheres.

Estudar as gerações profissionais é um dos caminhos que precisa ser percorrido para compreensão da cultura profissional e suas resistências tecidas na história. $\mathrm{O}$ atento exame 
do passado anuncia provocações para o momento presente. A reatualização do conservadorismo na sociedade e na profissão nos demanda um firme posicionamento em defesa do projeto ético-político, alinhando-nos a projetos societários emancipatórios na superação de todo tipo de preconceito, exploração, dominação e opressão, o que exige o enfrentamento concomitantemente do capitalismo, do patriarcado e do racismo, tendo por horizonte a emancipação humana, conhecendo os caminhos trilhados pela profissão e projetando coletivamente estratégias profissionais enraizadas no movimento da história e das lutas sociais.

\section{Referências}

AGUIAR, A. G. de. Serviço social e filosofia: das origens a Araxá. 5 ed. São Paulo: Cortez, 1995.

BARDIN, L. Análise de Conteúdo. São Paulo: Edições 70, 2016.

CASTRO, M. M. História do serviço social na América Latina. 12 ed. São Paulo: Cortez, 2011.

CISNE, M. Gênero, Divisão Sexual do Trabalho e Serviço Social. 1 ed. São Paulo: Outras Expressões, 2012.

CISNE, M.; SANTOS, S. M. M.. Feminismo, diversidade sexual e serviço social. São Paulo: Cortez, 2018.

COSTA, A. A. A. Depoimento. Rio de Janeiro, CPDOC/MPAS - SEAS, 2002. Disponível em: <http://www.fgv.br/cpdoc/historal/arq/Entrevista613.pdf> Acesso em: 19 de jan. de 2020.

CLOSS, T. T. Fundamentos do serviço social: um estudo a partir da produção da área. 2015. Tese (Doutorado). Pontifícia Universidade Católica do Rio Grande do Sul. Faculdade de Serviço Social. Programa de Pós-Graduação em Serviço Social. Porto Alegre, 2015.

CRUZ, N. de O. M. de V. Depoimento. Rio de Janeiro, CPDOC/MPAS - SEAS, 2002. Disponível em: <http://www.fgv.br/cpdoc/historal/arq/Entrevista551.pdf> Acesso em: 19 de jan. de 2020.

DAVIS, A. Mulheres, raça e classe. 1. ed. São Paulo: Boitempo, 2016.

ESCORSIM NETTO, L. O conservadorismo clássico: elementos de caracterização e crítica. São Paulo: Cortez, 2011.

FERREIRA, M. da G. L. de. Depoimento. Rio de Janeiro, CPDOC/MPAS - SEAS, 2002.

Disponível em: <http://www.fgv.br/cpdoc/historal/arq/Entrevista659.pdf> Acesso em: 19 de jan. de 2020. 
FREITAS, R. de C.; BARROS, N. V. Construindo uma profissão: o caso da Escola de Serviço Social da Universidade Federal Fluminense. Serviço Social e Sociedade, São Paulo, n. 97, p. 57-84, jan./mar., 2009.

GAMA, V. C. S. da. Depoimento. Rio de Janeiro, CPDOC/MPAS - SEAS, 2002. Disponível em: <http://www.fgv.br/cpdoc/historal/arq/Entrevista552.pdf > Acesso em: 19 de jan. de 2020.

GONZALEZ, L.. Por um feminismo afro-latino-americano In: Por um feminismo afro latino americano: ensaios, intervenções e diálogos. 1. ed. Rio de Janeiro: Zahar, 2020.

IAMAMOTO, M. V. Renovação e conservadorismo no serviço social: ensaios críticos. 11 ed. São Paulo: Cortez, 2011.

. O serviço social na contemporaneidade: trabalho e formação profissional. 24. ed. São Paulo, Cortez, 2013.

; CARVALHO, R. de. Relações sociais e serviço social no Brasil: esboço de uma interpretação histórico-metodológica. 41 ed. São Paulo: Cortez, 2014.

MACHADO, G. S. Serviço Social, formação brasileira e questão social: na cadência do pioneirismo carioca. 2015. Tese (Doutorado). Universidade Federal do Rio de Janeiro. Escola de Serviço Social. Programa de Pós-Graduação em Serviço Social. Rio de Janeiro, 2015.

MARTINELLI, M. L. O uso de abordagens qualitativas na pesquisa em serviço social. In: MARTINELLI, M. L. (Org.). Pesquisa qualitativa: um instigante desafio. São Paulo: Veras, 1999.

. Serviço social: identidade e alienação. São Paulo: Cortez, 2003.

MARX, K. O 18 de Brumário de Luís Bonaparte. Tradução de Nélio Schneider. São Paulo : Boitempo, 2011.

MENDONÇA, E. G. de M. Depoimento. Rio de Janeiro, CPDOC/MPAS - SEAS, 2002. Disponível em: <http://www.fgv.br/cpdoc/historal/arq/Entrevista612.pdf > Acesso em: 19 de jan. de 2020.

MORAES, M. de L. A. de. Depoimento. Rio de Janeiro, CPDOC/MPAS - SEAS, 2002. Disponível em: <http://www.fgv.br/cpdoc/historal/arq/Entrevista614.pdf> Acesso em: 19 de jan. de 2020 .

NETTO, J. P.. Capitalismo Monopolista e Serviço Social. 8 ed. São Paulo: Cortez, 2011.

PINTO, C. R. J. Uma história do feminismo no Brasil. São Paulo: Fundação Perseu Abramo, 2003.

REIS, A. P. A. P. R.. Depoimento. Rio de Janeiro,CPDOC/MPAS - SEAS, 2002. Disponível em: <http://www.fgv.br/cpdoc/historal/arq/Entrevista660.pdf> Acesso em: 19 de jan. de 2020.

SAFFIOTI, H.. Gênero patriarcado violência. 2. ed. São Paulo: Expressão Popular, 2015. 
SCHEFFER, G. Serviço Social e Dona Ivone Lara: o lado negro e laico da nossa história profissional. Serviço Social e Sociedade, n. 127, p. 476-495, set./dez. 2016.

VIEIRA, A. C. de S. Serviço social em Pernambuco: particularidades da formação e inserção profissional dos anos 1940 aos 1980. Serviço Social e Sociedade, São Paulo, n. 95, p. 77-96, set., 2008.

YAZBEK, M. C.; MARTINELLI, M. L.; RAICHELIS, R. O serviço social brasileiro em movimento: fortalecendo a profissão na defesa de direitos. Serviço Social e Sociedade, São Paulo, n. 95, p. 5-32, set., 2008.

YAZBEK, M. C. Fundamentos históricos e teórico-metodológicos do serviço social. In: CFESS/ABEPSS. Serviço social: direitos sociais e competências profissionais. Brasília: CFESS/ABEPSS, 2009. 